University of Nebraska - Lincoln

DigitalCommons@University of Nebraska - Lincoln

Faculty Publications, Department of Psychology

Psychology, Department of

February 1998

\title{
Repeated Testing in Eyewitness Memory: A Means to Improve Recall of a Negative Emotional Event
}

\author{
Brian H. Bornstein \\ University of Nebraska-Lincoln, bbornstein2@unl.edu \\ Lesley M. Liebel \\ Louisiana State University \\ Nikki C. Scarberry \\ Texas Christian University
}

Follow this and additional works at: https://digitalcommons.unl.edu/psychfacpub

Part of the Psychiatry and Psychology Commons

Bornstein, Brian H.; Liebel, Lesley M.; and Scarberry, Nikki C., "Repeated Testing in Eyewitness Memory: A Means to Improve Recall of a Negative Emotional Event" (1998). Faculty Publications, Department of Psychology. 177.

https://digitalcommons.unl.edu/psychfacpub/177

This Article is brought to you for free and open access by the Psychology, Department of at DigitalCommons@University of Nebraska - Lincoln. It has been accepted for inclusion in Faculty Publications, Department of Psychology by an authorized administrator of DigitalCommons@University of Nebraska - Lincoln. 


\title{
Repeated Testing in Eyewitness Memory: A Means to Improve Recall of a Negative Emotional Event
}

\author{
Brian H. Bornstein, Lesley M. Liebel, and Nikki C. Scarberry \\ Louisiana State University
}

Submitted January 1997; accepted July 2, 1997

\begin{abstract}
SUMMARY
Participants viewed either a violent, arousing film or a non-violent, control version of the same film. After viewing the film, they made three successive attempts to recall details of the event. Participants who were exposed to the negative emotional event were better than control participants at recalling details of the event itself, but they were worse at recalling details that preceded or followed the violence. Both groups of participants recalled significantly more information over successive recall attempts, suggesting that memory impairment due to arousal can be alleviated by repeated testing. Repeated testing was also associated with a small but reliable increase in memory intrusions. The implications of these findings for research on hypermnesia and on the relationship between arousal and memory are discussed.
\end{abstract}

A common characteristic of crimes is that they are upsetting to those who witness them. Because of this fact, considerable research has specifically addressed the effect of negative emotional events on eyewitness memory (for reviews, see Christianson, 1992; Deffenbacher, 1983). ${ }^{1}$ Despite widespread belief that certain traumatic events will be remembered well precisely because of their emotional component, recent research on these so-called "flashbulb" memories indicates that they may not be remembered especially well (Neisser and Harsch, 1992). The bulk of the research on arousal and memory for events indicates, on the contrary, that emotional stress has a detri-

Correspondence: Dr Brian Bornstein, Department of Psychology, University of Nebraska-Lincoln, 238 Burnett Hall, Lincoln NE 68588-0308 USA; email: bbornstein2@unl.edu. The second and third authors contributed equally to the project. The order in which their names appear was determined by the flip of a coin. Nikki Scarberry is now in the Department of Psychology at Texas Christian University. We are grateful to the MCEG/Sterling film production company, for granting us permission to use and modify one of their films in creating the materials for this study.

${ }^{1}$ As Christianson (1992) points out, terms such as "emotional," "stressful," "violent," "traumatic," and "arousing" have been used more or less interchangeably in the eyewitness literature, with regard both to the events observed by participants and to participants' subjective and physiological responses. Following Christianson (1992), in this paper the term "negative emotional event" refers broadly to "events that are new, unexpected, and potentially threatening" (p. 284) and subsumes all of the above terms. "Emotional stress" (or arousal) is defined as "a consequence of a negative emotional event, in which the person experiences a certain degree of stress or distress with concurrent autonomic-hormonal changes" (p. 285). 
mental effect on memory for details of a negative emotional event (e.g., Christianson and Nilsson, 1984; Clifford and Hollin, 1981; Clifford and Scott, 1978; Loftus and Burns, 1982). However, there are considerable variations in what information is most affected by arousal (Christianson, 1992). Some studies have found impaired memory due to arousal for information immediately preceding a stressful event, or "retrograde" impairment (e.g., Loftus and Burns, 1982); while other studies have found impaired memory for information immediately following a stressful event, or "anterograde" impairment, in the absence of any retrograde deficit (e.g., Christianson and Nilsson, 1984; Kramer, Buckhout, Fox, Widman \& Tusche, 1991).

For example, Loftus and Burns (1982) evaluated the impact of a disturbing film clip on both recall and recognition. Participants watched a videotape in which a bank robbery was depicted in either a non-violent or violent manner. The action in the video was matched from the time of the robbery until the perpetrator's escape into the parking lot, at which point the two conditions diverged: the violent film ended with the shooting of a bystander, while the non-violent film flashed back to the inside of the bank. Both conditions contained a designated critical item that was displayed seconds before the conditions diverged. The critical item was remembered less well in the violent than in the non-violent condition, as measured by both recall and recognition.

Despite the general tendency for negative emotional events to have a deleterious effect on memory for information that precedes or follows those events (Christianson, 1992), the emotionally arousing event itself tends to be remembered well, compared to a corresponding, neutral control condition (Burke, Heuer and Reisberg, 1992; Christianson, 1992; Heuer and Reisberg, 1990). Good eyewitness memory for emotional events themselves has been found in both field studies (Christianson and Hübinette, 1993; Yuille and Cutshall, 1986) and laboratory simulations, as well as in some studies of flashbulb memories (e.g., Larsen, 1992); furthermore, it may persist for several months after the event (Christianson and Loftus, 1987; Yuille and Cutshall, 1986).

These opposing effects of arousal — that is, enhanced memory for the arousing event itself but impaired memory for information that comes before and after it - appear to be due, at least in part, to the relative importance of different pieces of information within the context of the event as a whole (Christianson, 1992). Specifically, memory for central or thematic information tends to be improved by emotional arousal (Christianson and Loftus, 1987, 1991; Heuer and Reisberg, 1990), while memory for more peripheral information tends to benefit less (Heuer and Reisberg, 1990) and may even be impaired (Christianson and Loftus, 1991). Because the most salient and central information contained in a violent event is typically the violence itself, that information is remembered well, but at the expense of less important details that are tangentially, if at all, related to the violence. This pattern is particularly likely to be true at short retention intervals. There is some evidence that the benefit of arousal increases with longer retention intervals (Christianson, 1984) with a corresponding decrease over time in any disadvantages due to arousal (Burke et al., 1992) — but effects of retention interval are not very robust (Burke et al., 1992).

A real-world concomitant to increasing delay intervals is that eyewitnesses are often asked, by the police and others, to recollect on multiple occasions what they have seen. Although Burke et al. (1992) found no benefit of repeated testing for remembering details of an event, other research suggests that eyewitnesses do remember more 
over multiple recall attempts (Dunning and Stern, 1992; Eugenio, Buckhout, Kostes and Ellison, 1982; Scrivner and Safer, 1988; Turtle and Yuille, 1994). Furthermore, the gains in recall tend not to be accompanied by an increase in the number of errors (Dunning and Stern, 1992; Scrivner and Safer, 1988; Turtle and Yuille, 1994; but see Eugenio et al., 1982). For example, Scrivner and Safer (1988) evaluated the effects that repeated testing has on eyewitnesses' recall of a violent event. After viewing a filmed negative emotional event in which three people were shot, participants made four recall attempts. The filmed event was divided into four stages: initial activity, previolence, during violence, and postviolence. There were net gains in recall for information in all four stages of the film; i.e., the retrieval in successive recall attempts of previously unreported information exceeded the forgetting of previously retrieved information.

Scrivner and Safer (1988) explained their results in terms of "hypermnesia," which refers to increased net recall over longer retention intervals (Payne, 1987). The critical factor in eliciting hypermnesia is not merely increasing retention intervals, per se, but multiple overt or covert retrieval attempts (Payne, 1986; Roediger and Payne, 1982). Because hypermnesia is a more robust phenomenon when pictures, rather than words, are used as stimuli (Erdelyi and Becker, 1974; Payne, 1986, 1987), it is not surprising that it is obtained using dynamic pictorial stimuli such as crime films. However, a limitation of Scrivner and Safer's study, as well as other studies addressing the effects of repeated testing on eyewitness memory (e.g., Dunning and Stern, 1992; Eugenio et al., 1982; Turtle and Yuille, 1994), is that they did not expose a control group of participants to a non-violent event. Without such a comparison, it is impossible to know whether the increase in amount recalled over attempts is greater than, less than, or the same as it would be in the absence of arousal.

According to Payne (1987), "a relatively consistent finding in the hypermnesia literature is that in many cases, any variable that raises performance levels also leads to a greater hypermnesic effect" (p. 12; see also Roediger, Payne, Gillespie and Lean, 1982). Extrapolating from this finding, it seems reasonable to predict that any variable that lowers performance levels will reduce hypermnesia. Although hypermnesia has been demonstrated for both arousing (Scrivner and Safer, 1988) and neutral stimuli, such as pictures and words (Payne, 1987; Roediger and Payne, 1982), the effect of repeated testing on memory for arousing versus non-arousing information has not been directly compared. Such a comparison is of both theoretical and empirical interest, given the somewhat equivocal, yet undeniable, effects of arousal on eyewitness memory in general (Christianson, 1992; Deffenbacher, 1983).

The present study was designed as a replication and extension of the results obtained by Scrivner and Safer (1988). Consistent with Scrivner and Safer's procedure, participants viewed a violent film clip and then performed a series of recall tests. In order to assess the potentially mitigating effect of repeated testing on memory impairment due to arousal, an additional group of participants performed the same tasks after viewing a neutral version of the film. We made the following three predictions: first, recall of information prior to and following the violent event would be worse for participants viewing the violent event than for participants in the control condition (i.e., the negative emotional event would produce both retrograde and anterograde impairment); second, recall of the key event itself would be better for participants in 
the violent condition; third, recall would improve over successive recall trials. Furthermore, the benefit of repeated testing was predicted for participants viewing both the violent and non-violent events. Because previous research indicates that arousal has divergent effects on overall memory performance (Christianson, 1992), no specific prediction was made as to whether the effect of repeated testing would be greater for participants viewing the violent or non-violent event.

\section{METHOD}

\section{Participants}

The participants were 111 undergraduate psychology students who participated for extra course credit. Three participants failed to follow instructions, leaving 108 participants for analysis. Prior to the experiment, all participants signed consent forms, which indicated that the experiment might involve presentation of a filmed violent event. ${ }^{2}$ They were also informed that if they became upset during the experiment, they could terminate their participation at any time without penalty. All participants signed the consent form and completed the experiment.

\section{Materials and design}

Participants viewed a short scene from an R-rated film. The film was chosen because it met several important criteria: first, it contained a violent scene that could stand on its own, allowing it to be viewed apart from the preceding and subsequent scenes; second, the scene could be logically segmented into events leading up to the violence, the violent event itself, and events following the violence; third, all three segments were rich in details, for which participants' memory could be tested; and fourth, the scene could be plausibly edited (with the permission of the film company), whereby a non-violent event from a related scene in the film was substituted for the middle segment to create a non-violent control condition.

Participants viewed either the Violent version ( $1 \mathrm{~min} 33 \mathrm{sec}$ ) or the Control version (1 min $31 \mathrm{sec}$ ) of the film. Following previous research (e.g., Heuer and Reisberg, 1990; Scrivner and Safer, 1988), both versions were divided into three fairly discrete segments: initial, middle, and concluding. The initial and concluding segments were identical across conditions. The conditions differed solely in the content of the middle segment. In the original (violent) version of the film, the middle segment began when a man pulled a gun from under his cloak. He then killed one man and aimed the gun at another man (a priest) before backing away; at this point the concluding segment began. In the control condition, this middle segment was replaced by a non-violent segment that contained the same characters in the same setting and was of approximately equal duration. For scoring purposes, discrete details contained in the scene were

\footnotetext{
${ }^{2}$ It was deemed ethically necessary to warn participants that they might witness a violent event. It is possible that this warning created certain expectations on the part of the participants that might have biased their memory for the event. However, we doubt that it is a serious problem because participants in the Control condition, who were actually exposed to violence, received the same warning; hence any resultant bias would be the same for both groups. In addition, our major findings replicate those of previous research, both where such a warning was given (Scrivner and Safer, 1988) and where it apparently was not (Dunning and Stern, 1992).
} 
identified for both versions of the film (cf. Scrivner and Safer, 1988). The details were agreed upon by all three authors, as well as a colleague enlisted for this purpose who was blind to the experimental hypotheses. The details for each version of the film are listed in the Appendix; there were 45 details (by segment: 18-13-14) in the Violent condition and 43 details (by segment: 18-11-14) in the Control condition.

\section{Procedure}

Participants were tested in groups of up to 12 individuals. ${ }^{3}$ They were told to watch the film closely, as though they were actual eyewitnesses to the events. After viewing the film, participants performed a number of manipulation checks: they rated their level of anxiety and how upset they were (1 low, 5 high), both during and immediately after the film; they rated the level of violence in the film; and they were asked if they recognized the film or any of the actors in the scene (no participants correctly identified the film).

Participants then performed the initial recall task. This recall trial, as well as subsequent recall attempts, followed a modified forced recall format. Participants were told:

"You will now have 5 minutes to write down important details from the videotape on an answer sheet containing the numbers 1 to 45 [or 43, depending on condition]. Fill in each of the spaces with nonrepeating details and nonrepeating guesses. You must fill in each blank even if you have to guess. You are to write details rather than narratives. You are to write nontrivial details regardless of their order. You are to use 2- to 4-word responses. An example would be: instead of writing 'Jane went to the store to buy apples,' you would write on Line 1 'Jane went to the store' and on Line 2 'Jane bought apples.' Keep trying during the entire test, even when it seems difficult to recall more items."

This modified forced recall format is frequently used in research on hypermnesia (e.g., Erdelyi and Becker, 1974; Scrivner and Safer, 1988), in order to hold the guessing rate constant across trials. Although it may also induce a slight response bias and increase the number of false alarms, relative to free recall (Erdelyi, Finks and FeiginPfau, 1989), many participants self-corrected for this tendency by stopping short of the requested number of responses when they ran out of information to report. In any case, the likelihood of obtaining hypermnesia does not differ depending on the type of recall test used (Payne, 1987).

After completing the first recall trial, participants were provided with a 5-minute "think" period (Erdelyi and Becker, 1974; Eugenio et al., 1982), during which they were instructed to "think back on the scene you witnessed . . . to see if you can remember any better after thinking for a while." They were not allowed to make any written notations during the "think" period but were advised to recreate the scene mentally. After the "think" period, participants rated their current level of anxiety and how upset they were, followed by a second recall trial that was identical to the first one. In addition, they were told to "try to improve total recall by recalling details that

\footnotetext{
${ }^{3}$ Because of unforeseen difficulties in obtaining legal permission to edit the tape, all of the participants in the Violent condition were run prior to participants in the Control condition. However, all participants were recruited in the same fashion and came from the same subject pool.
} 
had already been recalled on the first test and as many new details as possible." Following the second recall trial, participants engaged in a second 5-minute "think" period, again rated how anxious and upset they were, and made a third recall attempt.

After the third recall trial, participants were thanked and debriefed. The entire procedure took 30-45 minutes to complete.

\section{RESULTS}

\section{Manipulation checks}

Participants in the Violent condition rated the film as significantly more violent than participants in the Control condition, $t(106)=8.14, p<0.001$. To test whether the film's violence affected participants' arousal level, separate ANOVAs were run on their ratings of how anxious and upset they were (means are shown in Figure 1). These ratings were made for four different times: during the film, immediately after the film (these first two ratings were both made immediately after seeing the film), and just prior to the second and third recall attempts. Thus, time-of-rating was a within-subject variable; film condition was included as a between-subjects variable.

There was a main effect of film condition for both anxiety ratings, $F(1,105)=$ $13.26, p<0.001$, and upset ratings, $F(1,106)=15.43, p<0.001$, indicating that participants were made more anxious and upset by the Violent than by the Control film. There was also a main effect of time-of-rating for both anxiety ratings, $F(3,315)=$ $30.15, p<0.001$, and upset ratings, $F(3,318)=41.18, p<0.001$, indicating decreasing levels over time. Finally, there was a significant interaction between time-of-rating and film condition for both anxiety ratings, $F(3,315)=3.10, p<0.03$, and upset ratings, $F(3,318)=4.61, p<0.005$. These interactions indicated a greater difference between film conditions for the earlier than for the later rating times. Post-hoc pairwise comparisons indicated that participants who viewed the Violent film reported being more anxious and upset than those who viewed the Control film both while they were watching the film, $t \mathrm{~s}>3.70, p \mathrm{~s}<0.001$, and immediately afterwards, $t \mathrm{~s}>$

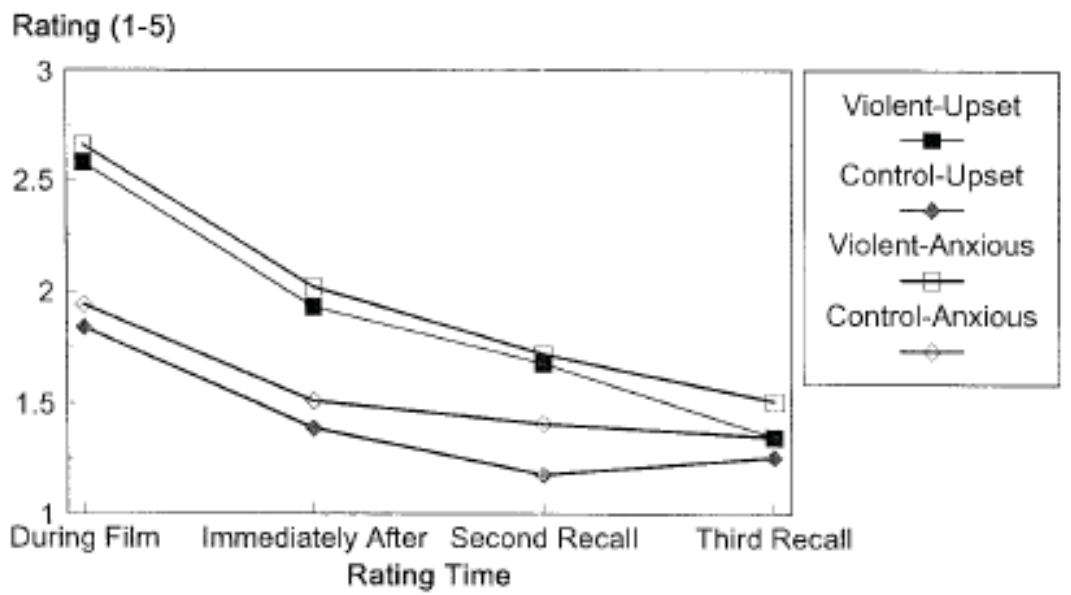

Figure 1. Participants' ratings of how anxious and upset they were in the Violent and Control film conditions 
$2.80, p \mathrm{~s}<0.01$; prior to the second recall attempt they were significantly more upset, $t(106)=3.40, p<0.001$, but only marginally more anxious, $t(106)=1.84, p<0.07$; and there was no difference between conditions prior to the third recall attempt, $t \mathrm{~s}<$ $1.01, p \mathrm{~s}>0.30$, which took place approximately 30 minutes after viewing the film.

These manipulation checks indicate that the Violent version of the film was indeed perceived by participants as more violent than the Control version. Furthermore, they suggest that the violence manipulation affected participants' subjective level of arousal, to the extent that arousal can be inferred from their self-reports. Self-report is a widely used measure of arousal (e.g., Kramer et al., 1991; Loftus and Burns, 1982) that covaries with physiological measures (Christianson, 1984).

\section{Recall of event details}

\section{Scoring procedure}

Two raters compiled a "scoring dictionary" that defined the acceptable statements for describing specific details from each segment of the scene (Scrivner and Safer, 1988). An example of an acceptable response would be to state that the murderer picked up "a bullet shell" (which it actually was) or "an object" off the ground, but not that he picked up "a piece of gold." Because the latter statement is an incorrect assertion corresponding to one of the relevant details, it would be scored as an error (cf. Turtle and Yuille, 1994). Errors were relatively rare overall and did not always clearly correspond to a specific segment; they were therefore tallied for the entire recall attempt and not broken down by film segment. Subjective statements that did not correspond to one of the critical details (e.g., "the priest was sad") were scored as neither correct nor incorrect. The two raters independently scored the third recall attempt for 78 of the 108 participants; inter-rater agreement on these data was quite high, with Pearson correlation coefficients for the three segments ranging from 0.94 to $0.96, p \mathrm{~s}$ $<0.001 .^{4}$ Therefore, the analyses reported below are based on the scoring of the rater who scored all of the data. Because the Violent and Control conditions differed in the total number of details, the number of details reported by participants for each segment was converted to a percentage.

\section{Effects of violence and multiple recall attempts on memory performance}

Participants' memory performance was assessed by a mixed ANOVA in which film segment (initial-middle-concluding) and recall trial (three levels) were within-subject variables and film condition (Violent-Control) was a between-subjects variable (means are shown in Table 1). There was a significant main effect of recall trial, $F(2$, $212)=15.52, p<0.001$. Specifically, participants recalled more information over successive trials $(M \mathrm{~s}=20.0 \%, 22.7 \%$, and $24.3 \%$ of the total number of details, respectively), as indicated by a significant linear contrast, $F(1,106)=26.19, p<0.001$. Recall trial did not interact with either film segment or film condition, indicating equivalent increases in recall performance across film segments and regardless of whether the film contained violence.

\footnotetext{
${ }^{4}$ Participants' condition was evident from the content of their responses. However, the scoring dictionary was created to be sufficiently objective and comprehensive to preclude problems of experimenter bias.
} 
Table 1. Mean percentage of details recalled (by segment) and mean number of errors across trials in the Violent and Control conditions

\begin{tabular}{|c|c|c|c|c|c|c|}
\hline \multirow[b]{3}{*}{ Measure and segment } & \multicolumn{6}{|c|}{ Recall trial } \\
\hline & \multicolumn{2}{|c|}{1} & \multicolumn{2}{|c|}{2} & \multicolumn{2}{|c|}{3} \\
\hline & Violent & Control & Violent & Control & Violent & Control \\
\hline \multicolumn{7}{|l|}{ Mean recall (percent) } \\
\hline Initial segment & 20.6 & 26.4 & 23.7 & 27.8 & 24.5 & 31.0 \\
\hline Middle segment & 24.2 & 9.3 & 26.5 & 9.4 & 25.9 & 11.6 \\
\hline Concluding segment & 15.8 & 20.0 & 19.4 & 24.9 & 20.8 & 27.5 \\
\hline Mean number of errors & 1.0 & 1.4 & 1.1 & 1.5 & 1.5 & 1.6 \\
\hline
\end{tabular}

Errors were not classified by segment. Standard deviations ranged from 10.8 to 15.8 for recall, and from 0.96 to 1.28 for errors.

There was also a significant main effect of film segment, $F(2,212)=26.39, p<$ 0.001 . Participants recalled $25.5 \%$ of the details in the initial segment, $18.2 \%$ of the details in the middle segment, and $21.2 \%$ of the details in the concluding segment; both linear and quadratic contrasts on participants' recall scores as a function of film segment were significant, $F_{\mathrm{s}}(1,106)=16.58$ and 34.93 , respectively, $p \mathrm{~s}<0.001$. Although the main effect of film condition was not significant, $F(1,106)<1$, the main effect of film segment was qualified by a significant interaction between segment and film condition, $F(2,212)=62.18, p<0.001$, which is illustrated in Figure 2. It was predicted that recall would be better in the Control condition for the initial and concluding segments, but worse in the Control condition for the middle segment; planned $\mathrm{t}$-tests were therefore performed between conditions for each segment. As predicted, recall of information in both the initial, $t(106)=2.94, p<0.005$, and concluding segments, $t(106)=2.59, p=0.01$, was better for participants who viewed the Control film. Control participants' mean recall was $28.4 \%(S D=9.4)$ of the details in the ini-

\section{Percent Correct (Averaged over all Recall Trials)}



Figure 2. Recall performance (percent correct) for details of the three film segments in the Violent and Control film conditions 
tial segment and $24.1 \%(S D=11.6)$ of the details in the concluding segment, as opposed to means of $22.9 \%(S D=10.0)$ and $18.7 \%(S D=10.3)$, respectively, for participants in the Violent condition. However, participants' recall for the middle segment was significantly better in the Violent $(M=25.5 \%, S D=12.3)$ than in the Control $(M$ $=10.1 \%, S D=10.6)$ condition, $t(106)=6.91, p<0.001$.

Participants' error scores were analyzed in a mixed ANOVA with recall trial as a withinsubject variable and film condition as a between-subjects variable (see Table 1 for means). There was a main effect of film condition $F(1,106)=4.06, p<0.05$, indicating more errors by participants who viewed the Control film $(M=1.52, S D=0.94)$ than by those who viewed the Violent film $(M=1.17, S D=0.84)$. There was also a main effect of recall trial, $F(2,212)=3.18, p<0.03$. A significant linear contrast indicated that the number of errors increased over successive recall attempts, $F(1,106)=6.20, p<0.02(M \mathrm{~s}=1.18,1.29$, and 1.53 , respectively). The interaction between recall trial and film condition was not significant, $F(2,212)<1$. Although a potential increase in false recall is an important qualification in considering the benefits of repeated testing, it should be noted that overall error rates were fairly low, reaching a mean of $1.53(S D=1.27)$ errors on the third recall trial.

\section{DISCUSSION}

We obtained support for all three of our hypotheses. As predicted, participants who witnessed a negative emotional event recalled less information preceding and following the event than participants in a comparable control condition. Such anterograde and retrograde impairments due to arousal have been demonstrated previously (Christianson and Nilsson, 1984; Kramer et al., 1991; Loftus and Burns, 1982). However, participants who were exposed to the emotional event recalled more of the event itself than did control participants, and they made fewer errors. These dual effects of a violent, arousing event are consistent with previous research (Christianson, 1992). Arousal tends to confer an advantage on eyewitnesses in remembering details of the arousing event, which tend to be more central, while it helps less, and may even place witnesses at a disadvantage, in remembering more peripheral details (Christianson and Loftus, 1987, 1991; Heuer and Reisberg, 1990). In the present experiment — as well as in witnessing crimes in general - the violent event itself is undoubtedly perceived as central, while preceding and subsequent events are perceived as relatively peripheral (though they might, of course, be judged important in retrospect).

Our third prediction, that repeated testing would increase the amount recalled by participants in both the Violent and Control conditions, also received support. The number of details reported correctly increased linearly over recall trials for both groups. Thus, the present findings replicate previous research showing that repeated testing improves recall for both arousing events (Davis, 1990; Dunning and Stern, 1992; Scrivner and Safer, 1988; Turtle and Yuille, 1994) and neutral pictorial stimuli (Erdelyi and Becker, 1974; Payne, 1986, 1987).

Despite taking steps to control for the amount of guessing, repeated testing also led to a net increase in errors. Research on hypermnesia in eyewitness memory has yielded inconsistent findings regarding participants' propensity to make errors. Some researchers have obtained a net increase in the frequency of errors over successive recall attempts (Eugenio et al., 1982), while others have not (Dunning and Stern, 1992; Scrivner and 
Safer, 1988; Turtle and Yuille, 1994). This inconsistency might be explained, in part, by the observation that arousal increases some types of intrusions but decreases others (Heuer and Reisberg, 1990). There are two reasons not to be overly concerned by an increase in errors over repeated testing. First, even though errors did increase significantly in the present study, their overall frequency was relatively low, peaking at a mean of 1.53 errors on the third recall trial. Secondly, as noted by Turtle and Yuille (1994), an increase in new correct details outweighs a small increase in errors from a forensic perspective; new information can greatly aid an investigation, even if some of it turns out to be in error.

The interaction between the variables of recall trial and film condition was not significant; that is, repeated testing improved memory equally for participants in the Violent and Control conditions. In light of arousal's capacity to enhance memory for some types of information while inhibiting others (Christianson, 1992), the absence of an interaction in the present experiment between film condition and recall trial is not very surprising and may derive from these opposing effects of arousal on performance in general. However, separate post-hoc analyses for each film segment also failed to obtain a significant interaction between recall trial and film condition, $F_{\mathrm{s}}(2$, $212)<1$. Both for portions of the film where there was a detrimental effect of arousal (i.e., the initial and concluding segments) and where there was a beneficial effect of arousal (i.e., the middle segment), repeated testing benefited participants in the Violent and Control conditions equally. This finding has two implications: first, it indicates that although variables that improve overall memory performance may also tend to increase the effects of repeated testing (Payne, 1987; Roediger et al., 1982), they do not always do so (Payne, 1986). In particular, this relationship does not appear to hold for variables (such as arousal) that are capable of both raising and lowering memory performance. Secondly, the equivalent improvement in recall across conditions suggests, as has other research (e.g., Christianson, 1992), that there is something quite unique and complex about arousal's effects on memory.

Because in the present study participants' recall time was limited to $5 \mathrm{~min}$, the apparent hypermnesia that was obtained might not be found if participants' recall time had been unconstrained. Turtle and Yuille (1994, Experiment 2) found that if witnesses were given a constrained amount of time for each recall attempt (e.g., $7 \mathrm{~min}$, following the procedure used by Scrivner and Safer, 1988), there was a net gain in the amount recalled over successive attempts; that is, hypermnesia was obtained. However, there was no hypermnesia when recall time was not limited (Turtle and Yuille, 1994, Experiment 1). In general, hypermnesia does not occur when recall time is either very short or so long that participants reach asymptotic levels by the end of the first recall attempt (Payne, 1987; Roediger and Thorpe, 1978). Turtle and Yuille still found that, like participants whose recall time was limited, participants who were given unlimited time recalled significantly more information on successive attempts; however, it did not exceed the forgetting of old information. They therefore conclude that repeated testing leads to "reminiscence" but not to hypermnesia.

It was not the purpose of the present study to distinguish between hypermnesia and reminiscence (Payne, 1987; Turtle and Yuille, 1994); rather, the purpose was to compare the effects of repeated testing on memory for arousing and neutral stimuli. Our results, combined with those obtained by Turtle and Yuille (1994), suggest that eyewitnesses are equally likely to recall new information over successive recall attempts 
whether or not the witnessed event was arousing. The fact that new details are added over time - for both violent and non-violent events - is of greater forensic relevance than whether the recall of new details exceeds the forgetting of previously recalled details (i.e., the hypermnesia vs. reminiscence distinction; Turtle and Yuille, 1994). Because eyewitness events are so often arousing (Deffenbacher, 1983), the finding that repeated testing enhanced the retrieval of information - both for details that were disadvantaged due to arousal (i.e., details that preceded and followed the violent event) and for details that were at an initial advantage due to arousal (i.e., details concerning the violent event itself) — is potentially very useful. It suggests that the difficulty in remembering some aspects of a negative emotional event may derive more from impaired accessibility than from limited availability (Davis, 1990). The lack of an interaction between recall attempt and stimulus type (i.e., Violent-Control) indicates that repeated testing is a generally useful means of enhancing information retrieval, even for information that may have been encoded with varying degrees of success.

Encoding effects cannot be solely responsible for the effects of arousal on eyewitness memory; retrieval processes play a part as well (Christianson, 1992). For example, the retrieval of negative emotional events can be enhanced by using mnemonic techniques designed to facilitate retrieval (Fisher and Geiselman, 1992) or by reinstating the mood that was present when the event was initially encoded (Christianson, 1992). Unfortunately, mnemonic techniques require special training (Fisher and Geiselman, 1992), and mood induction especially if it involves hypnosis is often impractical and forensically undesirable. However, witnesses are frequently question by multiple investigators within a short period of time after witnessing a crime (e.g., first the responding police officer, then a detective, then someone from the prosecutor's office). The present findings add to the importance of retrieval processes in eyewitness memory by suggesting that the relatively simple procedure of deliberately requiring a witness to make repeated retrieval attempts can facilitate the retrieval of negative emotional events to the same extent as neutral events.

In conclusion, the present experiment produced three main findings. First, participants who witnessed a negative emotional event recalled less information prior to, and following, the event than did a group of participants who witnessed a comparable neutral event, but they recalled more information about the critical event itself. Secondly, repeated testing increased the amount participants recalled about either the arousing or the neutral event. Thirdly, repeated testing enhanced recall equally for participants who witnessed the negative emotional event or the neutral event. Arousal may impair memory in some circumstances and facilitate it in others (Christianson, 1992), but repeated testing benefits recall regardless of the nature of the witnessed event.

\section{REFERENCES}

Burke, A, Heuer, F., and Reisberg, D. (1992). Remembering emotional events. Memory \& Cognition, 20, $277-290$.

Christianson, S.-Å. (1984). The relationship between induced emotional arousal and amnesia. Scandinavian Journal of Psychology, 25, 147-160.

Christianson, S.-A. (1992). Emotional stress and eyewitness memory: a critical review. Psychological Bulletin, 112, 284-309.

Christianson, S.-Å., and Hübinette, B. (1993). Hands up! A study of witnesses' emotional reactions and memo- 
ries associated with bank robberies. Applied Cognitive Psychology, 7, 365-379.

Christianson, S.-Å., and Loftus, E. F. (1987). Memory for traumatic events. Applied Cognitive Psychology, 1, 225-239.

Christianson, S.-Å., and Loftus, E. F. (1991). Remembering emotional events: the fate of detailed information. Cognition and Emotion, 5, 81-108.

Christianson, S.-Å., and Nilsson, L. (1984). Functional amnesia as induced by a psychological trauma. Memory \& Cognition, 12, 142-155.

Clifford, B. R., and Hollin, C. R. (1981). Effects of the type of incident and the number of perpetrators on eyewitness memory. Journal of Applied Psychology, 66, 364-370.

Clifford, B. R., and Scott, J. (1978). Individual and situational factors in eyewitness testimony. Journal of Applied Psychology, 63, 352-359.

Davis, P. J. (1990). Repression and the inaccessibility of emotional memories. In J. Singer (Ed.), Repression and dissociation (pp. 387-403). Chicago: University of Chicago Press.

Deffenbacher, K. (1983). The influence of arousal on reliability of testimony. In S. Lloyd-Bostock (Ed.), Evaluating witness evidence (pp. 235-251). Chichester: Wiley.

Dunning, D., and Stern, L. (1992). Examining the generality of eyewitness hypermnesia: a close look at time delay and question time. Applied Cognitive Psychology, 6, 643-657.

Erdelyi, M. H., and Becker, J. (1974). Hypermnesia for pictures: incremental memory for pictures but not for words in multiple recall trials. Cognitive Psychology, 6, 159-171.

Erdelyi, M. H., Finks, J., and Feigin-Pfau, M. B. (1989). The effect of response bias on recall performance, with some observations on processing bias. Journal of Experimental Psychology: General, 118, 245-254.

Eugenio, P., Buckhout, R., Kostes, S., and Ellison, K. (1982). Hypermnesia in the eyewitness to a crime. Bulletin of the Psychonomic Society, 19, 83-86.

Fisher, R. P., and Geiselman, R. E. (1992). Memory enhancing techniques for investigative interviewing: the cognitive interview. Springfield, IL: Charles C. Thomas.

Heuer, F., and Reisberg, D. (1990). Vivid memories of emotional events: the accuracy of remembered minutiae. Memory \& Cognition, 18, 496-506.

Kramer, T. H., Buckhout, R., Fox, P., Widman, E., and Tusche, B. (1991). Effects of stress on recall. Applied Cognitive Psychology, 5, 483-488.

Larsen, S. F. (1992). Potential flashbulbs: memories of ordinary news as the baseline. In E. Winograd and U. Neisser (Eds.), Affect and accuracy in recall (pp. 32-64). Cambridge: Cambridge University Press.

Loftus, E. F., and Burns, T. E. (1982). Mental shock can produce retrograde amnesia. Memory \& Cognition, 10, 318-323.

Neisser, U., and Harsch, N. (1992). Phantom flashbulbs: false recollections of hearing the news about Challenger. In E. Winograd and U. Neisser (Eds.), Affect and accuracy in recall (pp. 9-31). Cambridge: Cambridge University Press.

Payne, D. G. (1986). Hypermnesia for pictures and words: testing the recall level hypothesis. Journal of Experimental Psychology: Learning, Memory and Cognition, 12, 16-29.

Payne, D. G. (1987). Hypermnesia and reminiscence in recall: a historical and empirical review. Psychological Bulletin, 101, 5-27.

Roediger, H. L., and Payne, D. G. (1982). Hypermnesia: the role of repeated testing. Journal of Experimental Psychology: Learning, Memory, and Cognition, 8, 66-72.

Roediger, H. L., and Thorpe, L. A. (1978). The role of recall time in producing hypermnesia. Memory \& Cognition, 6, 296-305.

Roediger, H. L., Payne, D. G., Gillespie, G. L., and Lean, D. S. (1982). Hypermnesia as determined by level of recall. Journal of Verbal Learning and Verbal Behavior, 21, 635-655.

Scrivner, E., and Safer, M. A. (1988). Eyewitnesses show hypermnesia for details about a violent event. Journal of Applied Psychology, 73, 371-377.

Turtle, J. W., and Yuille, J. C. (1994). Lost but not forgotten details: repeated eyewitness recall leads to reminiscence but not hypermnesia. Journal of Applied Psychology, 79, 260-271.

Yuille, J. C., and Cutshall, J. L. (1986). A case study of eyewitness memory of a crime. Journal of Applied Psychology, 71, 291-301. 


\section{APPENDIX}

\section{Details in the Violent and Control film conditions}

Initial segment (18 details)

1. Occurred during the day

2. It was a rainy day

3. Man puts flowers on grave

4. Man kneels on the ground

5. Man says something

6. Man kisses a picture

7. The picture is on the grave

8. A priest is walking around the cemetery

9. Priest sees the man kneeling

Middle segment

\section{Violent (13 details)}

1. Second man speaks to kneeler

2. Kneeler turns his head

3. Second man pulls gun from cloak

4. Gun has silencer on it

5. Second man shoots kneeler

6. He shoots him one time

7. Kneeler is wounded in chest or back

8. Blood spatters on statue

9. Kneeler falls onto grave

10. Killer aims at fallen man's head

11. Priest says "For God's sake, No!"

12. Killer aims gun at priest

13. Killer backs up
10. A man walks up behind the kneeling man

11. Second man is a white male

12. Second man wears a black robe

13. Second man wears a beret

14. Second man has a mustache

15. Second man has a beard

16. Second man has brown hair

17. Second man is of medium height

18. Second man is of medium build

\section{Film condition}

Control (11 details)

1. Second man speaks to kneeler

2. Kneeler turns his head

3. Priest looks up to the sky

4. Priest closes umbrella

5. Priest looks on the ground

6. Priest picks up something off ground

7. Priest places object on top of grave

8. Priest walks around a corner

9. Puddles seen on pathways

10. Priest shakes umbrella

11. Close-up of statues on graves

Concluding segment (14 details)

1. Second man/killer squats on ground

2. Second man/killer picks up something

3. Second man/killer backs away slowly

4. Second $\mathrm{man} / \mathrm{killer}$ walks off

5. Priest goes to fallen man

6. Fallen man is not dead yet

7. Priest starts to pray
8. A (third) man is standing behind a nearby grave

9. The man is watching the priest

10. The man has blond hair

11. The man wears an overcoat

12. The man wears a tie

13. The man wears a white shirt

14. The man is white

Note. The Violent and Control conditions were identical in their initial and concluding segments 